\title{
Curso de Análisis de Redes Sociales: Metodología y Estudios de Caso
}

\author{
I gnacio Ramos Vidal
}

Departamento de Psicología Social, Universidad de Sevilla ${ }^{\mathbf{1}}$

\section{Reseña:}

Paniagua López, J.A. (2013). Curso de Análisis de Redes Sociales: metodología y estudios de caso. Granada: Editorial Universidad de Granada. 252 pág.

Para alguien interesado en el Análisis de Redes Sociales (ARS) es una grata tarea el poder reseñar un manual que aborda este tópico editado en España, puesto que constituye un síntoma inequívoco del interés creciente de la comunidad académica de nuestro país en esta área. El texto viene a sumarse al aún reducido número de manuales y libros de aprendizaje escritos o traducidos al castellano, como es el caso del manual de autoformación en programas informáticos de ARS (Molina, Quiroga, Martí, Maya-Jariego \& de Federico, 2006) o la traducción al castellano del manual introductorio de Hanneman y Riddle (2005). Estos avances aunados al incipiente número de investigadores interesados en aplicar el ARS a sus estudios, hacen presagiar que esta metodología con profunda fundamentación teórica seguirá experimentando una expansión exitosa en los próximos años.

Centrándonos ya en la obra de Julián Antonio Paniagua que vamos a reseñar, a mi juicio una de sus mayores fortalezas es que surge de la inquietud y de las demandas identificadas durante la práctica docente del autor. Esto supone dos elementos positivos que de alguna forma están presentes a lo largo de todo el texto: (a) la necesidad de ofrecer formación en materia de ARS que pueda ser aplicable de forma práctica en diferentes áreas de conocimiento y (b) el hecho de que las obras de referencia como el manual de Wasserman y Faust (1994) pueden resultar demasiado áridas debido a la fundamentación matemática de los conceptos y procedimientos, y en consecuencia poco accesibles para una audiencia no

\footnotetext{
1 Contacto: Ignacio Ramos Vidal, Departamento de Psicología Social, Universidad de Sevilla, 41018,
} Sevilla, España. Dirección Electrónica ignacioramosvidal@hotmail.com 
especializada como suelen ser los estudiantes universitarios. Por lo tanto el libro trata de presentar las nociones básicas del ARS de una forma sencilla, empleando un lenguaje llano y haciendo uso de relativamente pocas expresiones matemáticas.

Debemos señalar que el texto está principalmente orientado a estudiantes e investigadores noveles que persigan introducirse de forma rápida en el ARS. En este sentido y como el propio autor afirma en el prólogo, el libro no trata de ofrecer nuevas técnicas y procedimientos que vengan a complementar - o a suplir- a los ya existentes, sino más bien trata de adaptar el contenido de los textos clásicos en los que se basa - fundamentalmente el manual de Wasserman y Faust- a una audiencia iniciática.

El libro consta de una primera parte de carácter teórico en la que se introduce al lector de forma gradual en los conceptos básicos del ARS, y una segunda parte práctica en la que el autor se sirve de un estudio de caso basado en el análisis de los vínculos entre empleados de una administración pública - en la que participó directamente el propio autor- para ilustrar los conceptos y técnicas abordados en el manual. Al final del libro se ofrecen dos ejercicios prácticos para que el usuario pueda practicar los conceptos y métodos ilustrados en el texto, utilizando el programa Ucinet (Borgatti, Everett \& Freeman, 2002). Esto supone que el libro además de ofrecer una fundamentación teórica suficiente, también facilita un soporte práctico para introducirse en el manejo de uno de los programas más extendidos para analizar datos reticulares. A continuación describiremos brevemente cada una de las secciones que dan forma al manual.

El autor utiliza la introducción como hilo conductor a través del cual presenta los orígenes del ARS desde los trabajos de Jacob Moreno y la Escuela de Manchester, hasta los avances de nuestra época. En este apartado se observa el interés del autor por exhibir las múltiples aplicaciones del ARS para estudiar la realidad social desde un enfoque estructural, es decir, en el que no sólo es de interés conocer cuáles son las características (atributos) de los actores que conforman el sistema, sino en poner atención a cómo se relacionan estos actores. Este cambio en la manera de entender el análisis de los fenómenos sociales supone afirmar por un lado que las relaciones que cada actor establece con los demás determinan la estructura de la red completa en la que se integran, y por otro que al participar en redes de alguna forma nuestro comportamiento relacional se ve influido por la estructura de todo el sistema (Mitchell, 1969).

El segundo apartado denominado "Conceptos básicos: la teoría de grafos" se dedica a exponer otro de los referentes fundacionales del ARS como la explicación a través 
de la visualización de las relaciones. Después de un breve repaso por los orígenes de la teoría de grafos en los que se citan entre otros los trabajos de Frank Harary, se le presentan al lector conceptos esenciales para comprender los tipos de redes que pueden ser analizadas. En concreto se presentan las nociones de grafos orientados y no orientados, los tipos de matrices que usualmente se utilizan (Actores x Actores; Actores $x$ Eventos), conceptos sobre el posicionamiento de los actores en las redes sociales ( $p$. ej., equivalencia estructural y equivalencia regular), también se describen las principales medidas de cohesión (indicadores referentes a la red completa) y de centralidad (indicadores de los actores individuales). Este apartado que se basa esencialmente en los capítulos 4, 5 y 8 del manual de Wasserman y Faust (1994), es de suma importancia para adentrarse con garantías en el resto de secciones que dan forma al texto.

El tercer apartado se dedica a cuestiones prácticas para el planteamiento de una investigación en materia de ARS. Específicamente se describen algunos de los procedimientos para recolectar datos relacionales, prestando una atención especial a los tres elementos que deben ser definidos con claridad para desarrollar una investigación de este tipo: actores, atributos y relaciones. Uno de los factores clave para formular adecuadamente una investigación es delimitar adecuadamente los actores que compondrán la red que deseamos analizar. En segundo lugar es necesario identificar qué características de los actores (atributos) debemos analizar para conocer determinados procesos que pueden modular la configuración de la red como la homofilia (McPherson, Smith-Lovin \& Cook, 2001). Finalmente el investigador debe seleccionar qué tipo de relaciones quiere analizar y cuál es el contenido distintivo de cada interacción. Los elementos que se abordan en este apartado son de utilidad para la etapa inicial del diseño de investigación.

En los siguientes apartados el autor examina diferentes procedimientos analíticos para profundizar en las interacciones tanto a nivel de la red completa como a nivel diádico. Este tipo de análisis ayudan a comprender qué procesos modulan la estructura de la red y las interacciones entre diferentes redes. Sin resultar exhaustivo, este apartado facilita una aproximación inicial a la aplicación del análisis estadístico al ARS. De hecho Ucinet, al igual que otros programas, ofrece una amplia gama de herramientas de análisis estadístico (p.ej., análisis de clúster, análisis factorial, correlaciones, procedimiento de asignación cuadrática....) que son interesantes para conocer en profundidad tanto la configuración de la red como la interacción entre las variables que pueden incidir en dicha configuración. De igual modo se puede afirmar que el tono descriptivo empleado por el autor y la 
utilización de ejemplos prácticos e intuitivos ayudan a la comprensión de las técnicas y procedimientos expuestos.

Antes de iniciar la parte práctica del final, el autor incluye una sección dedicada en exclusiva a la interpretación de datos e indicadores. Esta sección es un acierto en la medida en que resulta de utilidad para dotar de sentido a la gran cantidad de resultados que se pueden obtener a partir del análisis de datos relacionales. De hecho este es uno de los puntos que más inquietud puede generar en aquellas personas que se enfrentan por primera vez a los resultados generados a través de Ucinet o de otros programas. En este sentido es relativamente fácil accionar los comandos del programa y obtener multitud de medidas tanto de la red completa como de los actores individuales, más difícil resulta dotar de significado a estos indicadores y saber qué implica que un actor sea central o que exista un elevado nivel de equivalencia estructural en el posicionamiento de los actores. No obstante, y como resulta lógico, la interpretación de estos indicadores dependerá en buena medida del tipo de relaciones que se estén analizando, dado que por ejemplo que una red sea altamente centralizada tendrá diferentes implicaciones en función del tipo de estructura que se esté evaluando. La conclusión del bloque teórico del manual se complementa con la descripción básica de una serie de lecturas clásicas. Se trata de una breve colección de artículos y libros que sirve de apoyo a los conceptos presentados en este primer bloque. A través de estos textos el lector podrá profundizar en las técnicas y procedimientos examinados en el libro.

Finalmente la segunda parte del manual se centra en analizar un estudio de caso en el que se examinan datos relacionales correspondientes a las interacciones reales entre los empleados del departamento de una administración pública. Esta parte del texto está organizada de tal forma que el lector pueda repasar las etapas de una investigación de ARS desde el inicio, y que además se emplean muchos de los conceptos, técnicas e indicadores previamente descritos. Esta organización supone pasar a la acción y emplear los instrumentos mencionados a un caso de estudio real. El libro se completa con dos ejercicios prácticos con los que el usuario podrá seguir practicando la introducción de datos y la elaboración de matrices con Ucinet y además podrán continuar afianzado los conocimientos desarrollados en el texto. En el primero se presentan a grosso modo las pautas para analizar redes sociales de internet como Facebook o Twiter, mientras que en el segundo se indican algunas reglas básicas para examinar la estructura de relaciones en contextos intraorganizativos. 
En resumen considero que la obra aquí reseñada puede recomendarse como manual introductorio a los conceptos básicos del ARS y que puede servir a los fines didácticos que en cierto modo motivaron la génesis del propio texto. Este interés por ser accesible y ameno, junto con el uso de expresiones coloquiales ayudan en la ardua tarea de adaptar obras que pueden resultar excesivamente complejas a un segmento interesado en utilizar el ARS pero que se encuentra en una fase de aproximación. Una de las virtudes del libro es combinar la necesaria explicación teórica con la iniciación en el manejo de un programa de análisis de datos relacionales. En consecuencia este manual puede servir tanto a los fines formativos para los que fue diseñado como para introducir en la metodología propia del ARS a nivel teórico y práctico.

\section{Referencias bibliográficas}

Borgatti, S.P., Everett, M.G., \& Freeman, L.C. (2002). UCINET VI Version 1.0. Natick, MA: Analytic Technologies.

Hanneman, R.A., \& Riddle, M.A. (2005). Introduction to social network methods. Riverside, CA: University of California, Riverside.

Mitchell, J. C. (Ed.) (1969). Social networks in urban settings. Manchester, UK: Manchester University Press.

Molina, J. L., Quiroga, A., Martí, J., Maya-Jariego, I., \& de Federico, A. (2006). (Eds.), Talleres de autoformación con programas informáticos de análisis de redes sociales. Bellaterra: Universitat Autonoma de Barcelona, Servei de Publicacions.

McPherson, M., Smith-Lovin, L. \& Cook, J.M. (2001). “Birds of a feather: Homophily in social networks". Annual Review of Sociology, 27, 415-444.

Wasserman, S., \& Faust, K. (1994). Social network analysis: Methods and applications. New York. Cambridge University Press. 